http://www.jfas.info

\title{
DYNAMIC SIMULATION OF CARBOCHLORINATION OF ZIRCONIA IN A PILOT PLANT FLUIDIZED-BED REACTOR
}

\author{
M.R Ghasemi, S.M. Ghoreishi* \\ Department of Chemical Engineering, Isfahan University of Technology, Isfahan 84156- \\ 83111, Iran
}

Published online: 15 February 2017

\begin{abstract}
Zirconium tetrachloride was produced via the chlorination of zirconia in a fluidized bed reactor in the presence of carbon. The fluidized bed zirconia carbochlorination reactor was modeled dynamically via a three-phase hydrodynamic flow assumption. The operating temperature (800-1200 $\left.{ }^{\circ} \mathrm{C}\right)$, reaction time (30-120 min) and mean particle size (MPS) (70-130 $\mu \mathrm{m})$ were chosen as the range of operating conditions. The comparison of reaction conversion with experimental measurements was used for model validation. An acceptable compatibility was observed between simulation results and experimental data. Investigation of fluidized bed operating conditions with the validated model was accomplished and the results indicated that smaller zirconia size, higher reactor temperature and reaction time improved chlorination rate. The optimum operating conditions were found to be $1200{ }^{\circ} \mathrm{C}, 120 \mathrm{~min}$ and $70 \mu \mathrm{m}$, in which the maximum zirconia conversion of $91.8 \%$ was obtained.
\end{abstract}

Keywords: Zirconia, Fluidized bed reactor, Carbochlorination, zirconium tetrachloride

\section{INTRODUCTION}

The fluidized bedtechnique has received considerable attention for producing zirconium tetrachloride, an intermediate in the production of zirconium metal, which is produced by carbochlorination of zirconia according to the following reaction:

$$
\mathrm{ZrO}_{2}+2 \mathrm{Cl}_{2}+2 \mathrm{C} \rightarrow \mathrm{ZrCl}_{4}+2 \mathrm{CO}
$$

\footnotetext{
Author Correspondence, e-mail: ghoreshi@cc.iut.ac.ir doi: http://dx.doi.org/10.4314/jfas.v9i1s.716
} 
The fluidized bed technique has many inherent advantages, including temperature uniformity, favorable heat transfer and solid handling, low pressure drop, and operational flexibility.

Modeling of fluidized bed is necessary for design and scale up. Among many models employed, the hydrodynamic flow models are the most satisfactory for describing the performance of abubbling fluidized bed [1]. This type of model describes and characterizes the parameters influencing the hydrodynamics of fluidized beds. Hydrodynamic models are divided into three categories i.e., single, two- and three-phase model. For dynamic simulation of fluidized bed three phases including: bubble, cloud and emulsion are considered. Based on this model, Davidson-Harrison model [2], Partridge-Row model [3], the Kunii-Levenspiel model [4], the Kato-Wen bubble assemblage model[5], the Chiba-Kobayashi bubble flow model [6], the shell model [7] have all been developed in accordance with different bubble dynamics.

There are some investigations that report on the chlorination of zirconia[8-15]. Several mathematical models have been developed to simulate the fluid dynamics and reaction phenomena in the fluid bed. Fuwa et al.[16] introduced the bubble assemblage model to interpret the selective chlorination of oxidized Ilmenite ore in the batch type fluidized bed. Rhee and Sohn [17] developed a more detailed model that incorporate the solid mixing. Youn and Park [18] developed a model to simulate the chlorination of rutile with coke in a fluidized bed. Jazini et al. [19] developed two two-phase hydrodynamic models for simulation of fluidized bed chlorination of zircon. They demonstrated that the plug-mixed model indicated a stronger correlation with experimental data.

The main objective of this work was to design and build a pilot-scale carbochlorination fluidized bed reactor and developing a hydrodynamic three-phase model to dynamicallysimulate the fluidized bed reactor. In this model, a particle size reaction rate expression, which takes into account the particle size distribution of solid, was incorporated to calculate the concentration profile of chlorine in the bed. The particle size distribution in bed was determined by a population balance. The model assumes that solid particles are wellmixed (CSTR) throughout the bed, but gas concentrations vary with the bed height (plug).Furthermore, the validated model was utilized to investigate the important operating parameters affecting the reactor performance. Therefore, it is possible via the application of the obtained model to pinpoint the appropriate conditions for reactor operation without any additional time consuming and expensive experiments. 


\section{EXPERIMENTAL}

\subsection{Materials}

The gases used for this study were Nitrogen (99.9\% purity) and $\mathrm{Cl}_{2}$ (99.9\% purity). The powdered materials were $\mathrm{ZrO}_{2}$ (Sooreh Co., Isfahan, Iran) (composition: $\mathrm{Zr}=73.9 \%$, $\mathrm{Fe}=0.18 \%, \mathrm{Si}=0.015 \%, \mathrm{Al}=0.01 \%$ and $\mathrm{Hf}=0.004 \%$ ) and carbon (composition: fixed carbon $=95.8 \%, \mathrm{Ash}=3.2 \%$, Volatile $0.6 \%$ and heating loss $=0.4 \%$ ). The BET surface areas of $\mathrm{ZrO}_{2}$ and carbon were determined to be $14.4 \mathrm{~m}^{2} / \mathrm{g}$ and $1.5 \mathrm{~m}^{2} / \mathrm{g}$, respectively (Sorptometer Kelvin 1042, ISO 9277-2010). The characterization (size and morphology) of the powdered $\mathrm{ZrO}_{2}$ and carbon were determined by scanning electron microscopy (SEM) and X-ray powder diffraction (XRD). Figs. 1and 2 show the SEM and XRD of the powdered materials in the reactor feed, respectively. The mixture of carbon/zirconia (20/80 wt. \%) was used to prepare briquettes using laboratory hydraulic press. Then the briquettes were powdered by means of a laboratory crusher to produce particles with mean size from 70 to $130 \mu \mathrm{m}$.

\subsection{Apparatus and procedure}

Fig. 3 shows the schematic representation of the pilot-scale fluidized bed reactor (FBR) used for the experimental investigation of carbochlorination of zirconia in semi-batch and continuous modes. The preheating part of the reactor vessel was $1.3 \mathrm{~cm}$ I.D., $6.4 \mathrm{~cm}$ O.D. and $40.6 \mathrm{~cm}$ long. The reaction section was $6.4 \mathrm{~cm}$ I.D., $11.4 \mathrm{~cm}$ O.D. and $55.9 \mathrm{~cm}$ long. The disengaging section was $11.4 \mathrm{~cm}$ I.D., $16.5 \mathrm{~cm}$ O.D. and $15.2 \mathrm{~cm}$ long. The reactor consists of two electrodes to introduce electric current into a fluidized bed of conductive particles. In the case of chlorination reactions, the bed of carbon particles provides both the necessary reluctant and the heating means. The reactor system is made of a hard graphite chlorination reactor, a bed resistance heating unit, two condensing unit, and auxiliary equipment for supplying and measuring the gases, feed, and power to the system. The graphite chlorination reactor tapered from a $6.35 \mathrm{~cm}$ diameter at the bottom to $11.43 \mathrm{~cm}$ in diameter at the top and was $123.19 \mathrm{~cm}$ high. A $1.27 \mathrm{~cm}$ hole in the bottom of reactor was used as a feed and fluidizing gas inlet. In order to achieve more uniform temperature throughout the reactor, a layer of fine graphite powder was built around the reactor. The second electrode for the heating system was at the center of the reactor. Openings at the top of the reactor also served as observation and exhaust ports. The reactor was mounted in a refractory-lined furnace shell with a $25 \mathrm{~cm}$ layer of fire brick insulation surrounding the reactor. The bed resistance heating system consisted of the electrode submerged in the bed material, the reactor wall which acts as the second electrode, a 800 ADC-power supply controlled by a variable transformer and 
auxiliary power measuring equipment. The volatilized chlorides were collected by two condensers.

The obtained powder of zirconia/carbon mixture was put in to the chlorination reactor and fluidized with nitrogen. Power was supplied to the heating unit and the bed heated to operating temperature. When the desired temperature was reached in the chlorination reactor, the nitrogen flow was replaced with chlorine. The chlorine flow rate was set to $2 \mathrm{~L} / \mathrm{min}$, which provided superficial space velocities of $5 \mathrm{~cm} / \mathrm{s}$ thorough the reactor. All experiments were carried out at the fixed $\mathrm{Cl}_{2}$ flow rate of $2 \mathrm{~L} / \mathrm{min}$. Table 1 shows the specifications of the pilot plant for the operation in semi-batch mode. The chlorine flow and the power to the reactor then were shut off and the system was cooled in nitrogen. The flow diagram of the pilot is shown in Fig. 4.

\section{MODEL FORMULATION}

In developing the model, a fluidized bed with the following features and assumptions are considered:

1- $\quad$ Simulation of fluidized bed carries out in dynamic mode. In order to drive optimum consumption rate of zirconia for simulation in dynamic mode; three-phase rigorous model is selected.

2- The bed consists of three regions: bubble, cloud and emulsion. The gases are exchanged among these regions.

3- The gas compositions in the bubble and emulsion phases change with bed height, but the solids are uniformly mixed throughout the bed.

4- Horizontal variations of gas concentrations in each phase can be neglected.

5- $\quad$ The bed is operated under isothermal condition due to the rapid mixing in the bed.

6- $\quad$ Pressure drop along the bed height is neglected.

7- Volume exchange, in the gas phase according to the reaction stoichiometry is considered.

8- Bubble diameter changes along the bed.

\subsection{Mass balance on bubble, cloud, and emulsion phase}

The generalized mass balance equation for gas in bubble, cloud, or emulsion phase element is as follows:

$($ Bulk flow in $)-($ Bulk flow out $)-($ Disappearance by reaction $) \pm($ Mass transfer $)=$ 
Mass changes during time

Fig.5 visualizes the differential element in in bubble, cloud, or emulsion phases.

The following equations have been derived in dynamic mode:

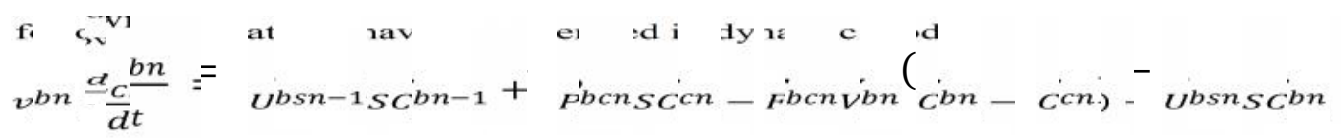

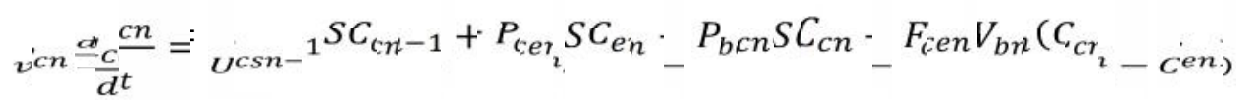

$$
\begin{aligned}
& +F_{b c n} V_{b n}\left(C_{b n}-C_{c n}\right)=K V_{c n} C i_{c n}=U_{c s n} S C_{c n} \\
& +\quad-\quad-\quad r
\end{aligned}
$$

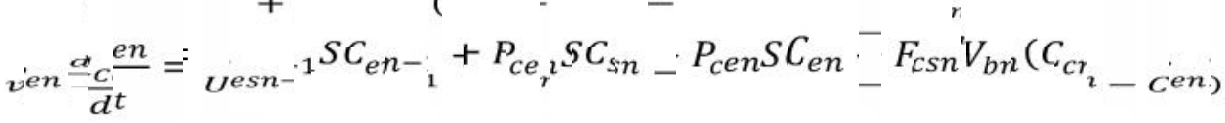

$$
\begin{aligned}
& +F_{c e n} V_{b n}\left(C_{c n}-C_{e n}\right)=K V_{e n} C i_{e n}-U_{e s n} S C_{e n}
\end{aligned}
$$

To solve above equations, $4^{\text {th }}$ order Runge-Kutta order was selected.Initial conditions for above equations were:

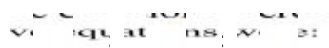

$$
\begin{aligned}
& \text { сьиo }=\mathrm{cco}=\mathrm{ceo}=\mathrm{co} \\
& c^{b o}=0 \\
& \bar{c}_{\text {cso }}=\bar{C}^{\circ}-{ }^{\circ} \\
& v_{\text {yeso }}=y^{\mathrm{oO}}-\text { ybso }^{\mathrm{css}}
\end{aligned}
$$

\subsection{Parameters used in the model}

a. Diameter along the bed was calculated based on Horio [20] correlation:

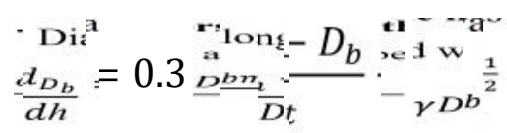

In equation $21, \gamma$ is $\gamma=7.68 \times 10^{-3} /\left(U_{m f} \sqrt{g}\right)$

b. Maximum bubble diameter, $\mathrm{D}_{\mathrm{bm}}$, was calculated by:

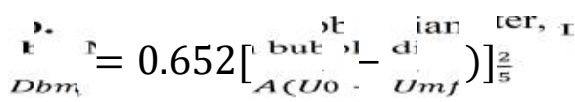

In above equation, $\mathrm{A}$ is cross sectional area. Initial bubble diameter is calculated by the following equation,

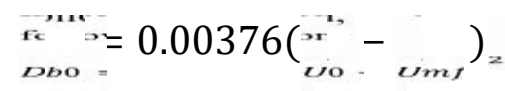

c. Gas superficial velocity in bubble phase [21]: 


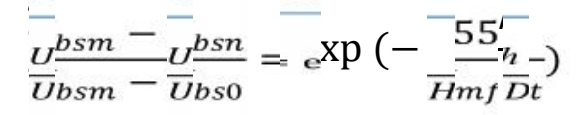

In which:

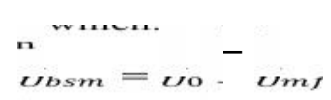

And

$$
\text { unso : }
$$

And

$$
) 9(
$$

$$
) 10(
$$

$$
\delta_{\mathrm{b} 0}=1-\mathrm{H}_{\mathrm{mf}} / \mathrm{H}_{\mathrm{f}}
$$

d. Gas superficial velocity in cloud phase $\left(\mathbf{U}_{\mathbf{c s n}}\right)$ :

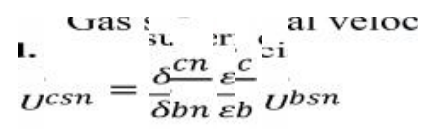

Gas superficial velocity in emulsion phase $\left(\mathrm{U}_{\mathrm{esn}}\right)$ :

As gas superficial velocity, $\mathrm{U}_{0}$, is the sum of gas superficial velocity in whole phases, gas superficial velocity in emulsion phase obtained by:

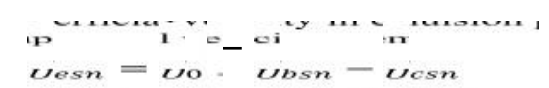

Upward gas velocity $\mathrm{U}_{\mathrm{bn}}[22]$ :

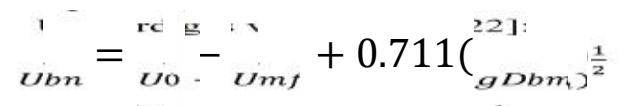

e. Volume fraction of each phase:

$$
\begin{aligned}
& \delta_{b n}=\frac{n_{I} s n}{U b n} .
\end{aligned}
$$

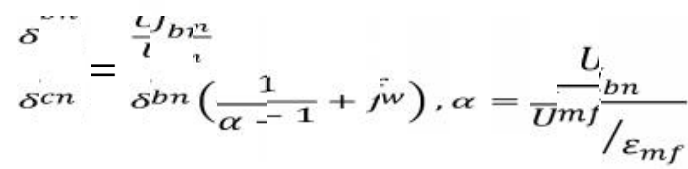

$$
\begin{aligned}
& \overline{\operatorname{sen}}_{\text {sen }}=1-{ }_{\text {son }}^{-\bar{c}}= \\
& \varepsilon_{m f}
\end{aligned}
$$

Which $f_{w}$ is the ratio of wake volume to bubble volume and is taken to be 0.25 in this study. The volume of each phase in a compartment may be calculated as

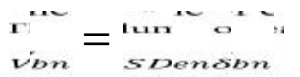
)17(

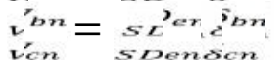
)18(
$v^{c n}=\sin ^{\sin } \sin ^{\mathrm{c} n}$
vén spensen 
The volume fraction of gas in the bubble phase is assumed to be one, and the volume fraction of gas in the cloud-wake and emulsion phases is assumed to be equal to that at minimum fluidization throughout the entire reactor

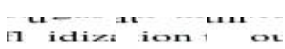

ec $=e e=e m$.

f. Height of bed expansion

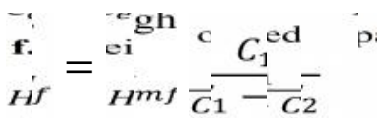

in which

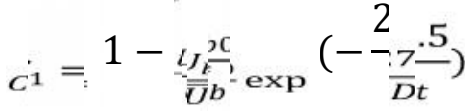

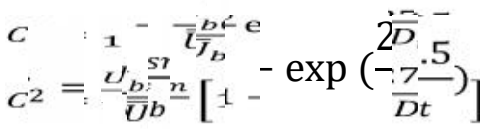

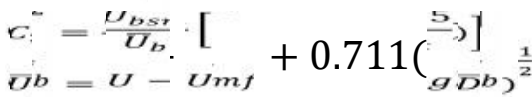

$$
\begin{aligned}
& \begin{array}{l}
\bar{U}^{b}=U \\
\bar{D}^{b}=D^{b m_{L}}
\end{array}
\end{aligned}
$$

\section{g. Gas interchange coefficients}

Ignoring the film diffusion contribution between the bubble and cloud phases, which is usually small as compared to the bulk flow term, the gas interchange coefficients, between the bubble and cloud-wake phases as well as the cloud-wake and emulsion phases, can be expressed as [23].

$$
\begin{aligned}
& { }_{1} \text { si is }{ }^{\mathrm{L}} \mathrm{l} \\
& \dot{F b c n}=2\left(\frac{U_{i}}{\bar{D} b n}\right)
\end{aligned}
$$

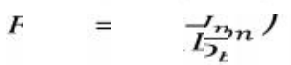

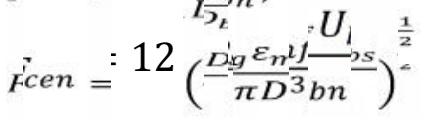

\section{h. Cross flow}

In order to satisfy the overall material balance at a given bed height, the cross-flow terms are necessary. The cross-flows may be evaluated as

$$
\begin{aligned}
& \text { Fibon }=\text { Ubsn - Ebsn-1 }
\end{aligned}
$$

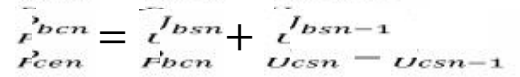

\section{METHOD OF NUMERICAL SOLUTION}

Proposed model for simulation of fluidized bed is illustrated in Fig. 6. Method of simulation is based on forward calculation in which parameters calculates for each segment of bed. Starts 
at distribution plate, input parameters are used to calculate concentration of gas of all phases for each increment. In the next step, input data updates and concentration of each phase calculate. Based on bubble diameter, length of each step is determined and as a result, sum of bubble diameter equal tolength of the bed. Calculation of gas concentration for total bed is derived during step time.

\section{RESULTS AND DISCUSSION}

In order to investigate the model authenticity, the model predictions using Bicerolu-Gauvin rate equation [9] were compared with the experimental results from pilot-scale chlorination reactor.

In Fig.7, the model predictions are shown to agree reasonably well with the experimental data. It should be pointed out that the model is not strictly tied to the correlations proposed for the estimation of hydrodynamic parameters. It is expected that prospective experimental investigations will lead to more accurate predictions, although the correlations utilized here have provided fairly good results.

Fig. 8 (a-c) show the effect of reaction time and temperature on the zirconia conversion at different zirconia particle sizes of 70, 100 and $130 \mu \mathrm{m}$, respectively. The deviation between the experimental data and mathematical modeling has been depicted in Fig. 8b.

The trend of Fig. 8 illustrates that decreasing MPS from $130 \mu \mathrm{m}$ to $70 \mu \mathrm{m}$, increases the conversion due to the availability of larger surface area for reaction. The average diameters of the zirconia particles used in the model were chosen according to the physical conditions of the pilot plant reactor of this study and Spink et al. [24]. But it is necessary to realize that there is a limit in the reduction of particle size due to the lack of bubbling fluidization and excessive entrainment in the reactor.

Temperature had an important operational parameter and it is necessary to establish the optimum temperature for the process. Increasing temperature causes higher reaction rate and consequently results in higher zirconia consumption and enhance zirconia conversion.

Increasing the chlorination time from $30 \mathrm{~min}$ to $120 \mathrm{~min}$ was found to be directly proportional to the amount of reacted zirconia.Fig. 8 shows the XRD analysis of the produced $\mathrm{ZrCl}_{4}$ in the carbochlorination process.

\section{CONCLUSION}

Using a kinetic equation developed by Bicerolu-Gauvin in the three-phase hydrodynamic model of a fluid bed and the population balance of solid particles, resulted numerical 
predictions which shows a close agreement with the experimental data. Furthermore, using the authenticated model developed in this study, the effects of different operating conditions, namely, (1) superficial gas velocity, (2) inlet chlorine concentration, (3) inlet zirconia particle size, and (4) reactor temperature on chlorine conversion and the flow rate of converted zirconia consumption were investigated and the results demonstrate that small zirconia size, high inlet gas velocity, and high reactor temperature enhance chlorination rate.

\section{NOMENCLATURES AND UNITS}

\begin{tabular}{|c|c|c|}
\hline A & $\mathrm{m}^{2}$ & Cross section area of bed \\
\hline $\mathrm{C}_{\mathrm{pi}}$ & $\mathrm{J} / \mathrm{mole} . \mathrm{K}$ & Specific heat capacity \\
\hline $\mathrm{C}$ & mole./m 3 & Concentration of chlorine \\
\hline $\mathrm{F}_{\mathrm{A} 0}$ & mole/s & Mole rate of chlorine \\
\hline $\mathrm{F}$ & $\mathrm{kg} / \mathrm{s}$ & Mass rate of solid \\
\hline $\mathrm{F}_{\mathrm{z}}^{\prime}$ & $\mathrm{g} / \mathrm{m}^{2} \cdot \mathrm{s}$ & $\begin{array}{l}\text { Rate of zirconia converted in bed per unit cross section area } \\
\qquad \text { of bed }\end{array}$ \\
\hline $\mathrm{H}_{\mathrm{f}}$ & $\mathrm{m}$ & Bed height \\
\hline $\mathrm{K}_{\text {be }}$ & $1 / \mathrm{m}^{3} \cdot \mathrm{s}$ & Interchange gas transfer coefficient \\
\hline $\mathrm{K}^{\prime \prime}\left(\mathrm{r}_{\mathrm{i}}\right)$ & $\mathrm{kg} / \mathrm{s}$ & Elutriation rate constant \\
\hline $\mathrm{n}$ & mole/s & Mole rate \\
\hline $\mathrm{p}\left(\mathrm{r}_{\mathrm{i}}\right)$ & $1 / \mu m$ & Size distribution function \\
\hline Q & $\mathrm{J} / \mathrm{s}$ & Heat generated in bed \\
\hline $\mathrm{R}_{\mathrm{t}}(\mathrm{C})$ & $\mathrm{m} / \mathrm{s}$ & Total shrinkage rate of zirconia particles of size $r_{i}$ in bed \\
\hline $\mathrm{R}_{\mathrm{b}}$ & $\begin{array}{l}\text { mole } \\
\mathrm{Cl}_{2} / \mathrm{m}^{2} . \mathrm{s}\end{array}$ & $\begin{array}{c}\text { Chlorine rate of consumption per unit surface area of } \\
\text { zirconia particles }\end{array}$ \\
\hline $\mathrm{r}$ & $\begin{array}{l}\text { mole } \\
\mathrm{Cl}_{2} / \mathrm{m}^{3} . \mathrm{s}\end{array}$ & Chlorine rate of consumption per unit volume of bed \\
\hline $\mathrm{r}_{i}$ & $\mathrm{~m}$ & Radius of particle $\mathrm{i}$ \\
\hline $\mathrm{T}$ & $\mathrm{K}$ & Temperature \\
\hline $\mathrm{u}$ & $\mathrm{m} / \mathrm{s}$ & Superficial gas velocity \\
\hline
\end{tabular}




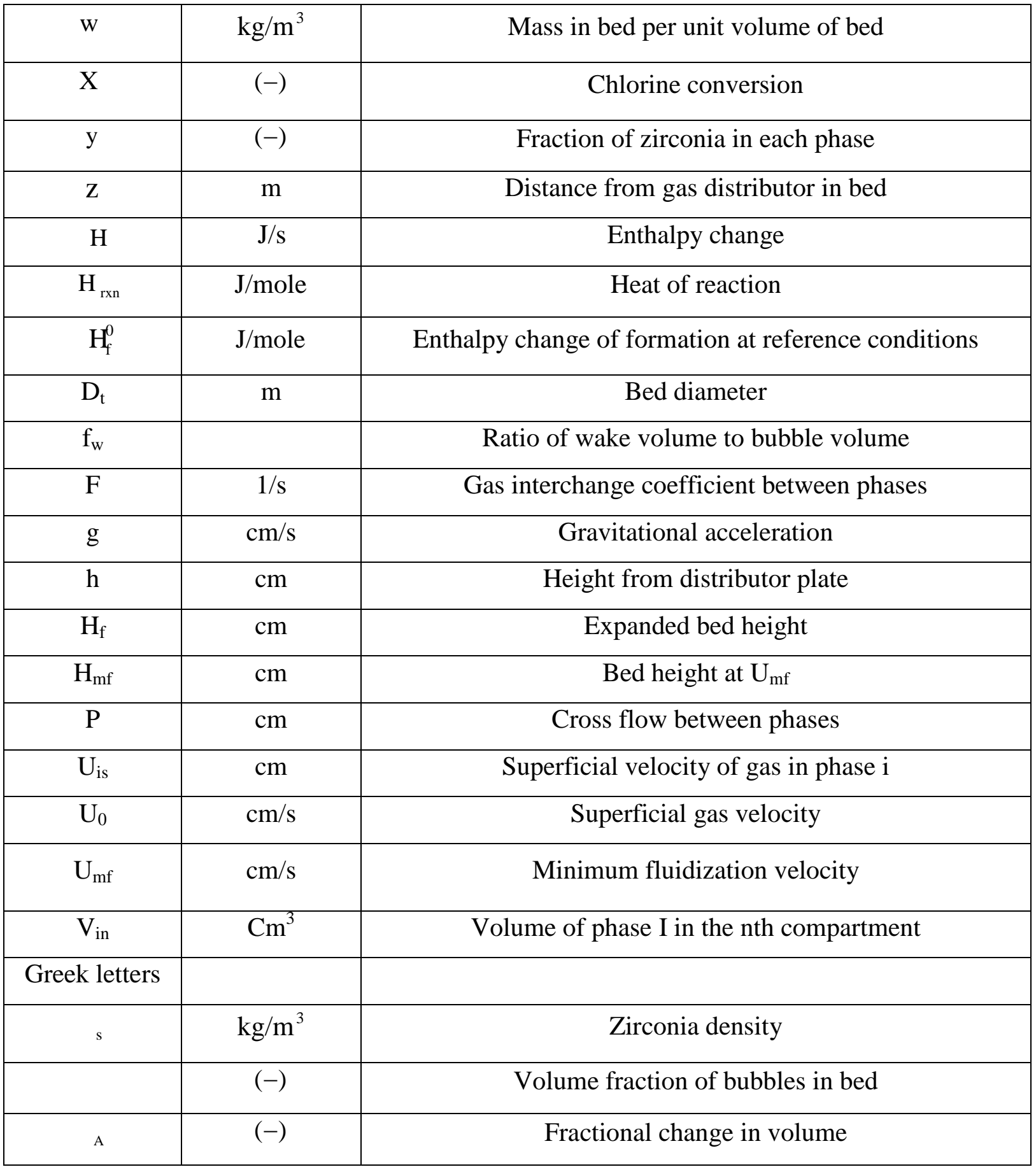

\section{ACKNOWLEDGMENTS}

The financial support provided for this project by Isfahan University of Technology (IUT) is gratefully acknowledged. 


\section{REFERENCES}

1- Werther, J. (2007). Fluidized Bed Reactors. Wiley VCH Verlag GmbH \& Co. KGaA.

2- Davidson, J. F., \& Harrison, D. (1963). Fluidized ParticlesCambridge Univ. Press, Cambridge.

3- Partridge, B. A., \& Rowe, P. N. (1966). Chemical reaction in a bubbling gas-fluidised bed. TRANSACTIONS OF THE INSTITUTION OF CHEMICAL ENGINEERS AND THE CHEMICAL ENGINEER, 44(9), T335-+.

4- $\quad$ Kunii, D. and Levenspiel, O. Fluidization Engineering, John Wiley \& Sons, New York (1969).

5- Kato, K., \& Wen, C. Y. (1969). Bubble assemblage model for fluidized bed catalytic reactors. Chemical engineering science, 24(8), 1351-1369.

6- Chiba, T. and Kobayashi, H. "Modeling of catalytic fluidized bed reactors", In: Proceedings of Int. Conf. on fluidization and its applications (1973).

7- Kanholy, S. K., Chodak, J., Lattimer, B. Y., \& Battaglia, F. (2012). Modeling and Predicting Gas-Solid Fluidized Bed Dynamics to Capture Nonuniform Inlet Conditions. Journal of Fluids Engineering, 134(11), 111303.

8- Jena, P. K., Brocchi, E. A., \& Reis, M. L. D. (1999). Kinetics of chlorination of zirconia in mixture with petroleum coke by chlorine gas. Metallurgical and Materials Transactions B, 30(3), 375-381.

9- Bicerolu, O., and Gauvin, W. H., "The Chlorination Kinetics of Zirconium Dioxide in the Presence of Carbon", Can J. Chem. Eng., 58, 357-366 (1980).

10- O'Reilly, A. J., Doig, I. D., \& Ratcliffe, J. S. (1972). The kinetics of the chlorination of zirconium dioxide in a static bed with carbon and chlorine. Journal of Inorganic and Nuclear Chemistry, 34(8), 2487-2495.

11- Bohe, A. H., Pasquevich, D. M., "An Apporoach to intrinsic kinetics of the zirconium Oxide carbochlorination”, Berichte Bunsen-Gesellschaft, 99, 1553-1558 (1995).

12- Biceroglu, O., \& Gauvin, W. H. (1980). Chlorination kinetics of zirconia in an RF chlorine plasma tail flame. AIChE Journal, 26(5), 734-743.

13- Pasquevich, D. M., Gamboa, J. A., \& Caneiro, A. (1992). On the role of carbon in the carbochlorination of refractory oxides. Thermochimica acta, 209, 209-222.

14- Pasquevich, D. M., \& Amorebieta, V. T. (1992). Mass spectrometric study of volatile products during the carbochlorination of zirconia. Berichte der Bunsengesellschaft für physikalische Chemie, 96(4), 530-533. 
15- Pasquevich, D. M., \& Caneiro, A. (1989). A thermogravimetric analyser for corrosive atmospheres and its application to the chlorination of $\mathrm{ZrO} 2-\mathrm{C}$ mixtures. Thermochimica Acta, 156(2), 275-283.

16- Fuwa, A. et al. "Kinetics of iron chlorination of roasted Ilmenit Ore, Fe2TiO5 in a fluidized bed", Metall. Trans. B, 9, 643-651 (1978).

17- Rhee, K. I., \& Sohn, H. Y. (1990). The selective chlorination of iron from llmenite ore by $\mathrm{CO}-\mathrm{Cl} 2$ mixtures: Part II. Mathematical modeling of the fluidized-bed process. Metallurgical and Materials Transactions B, 21(2), 331-340.

18- Youn, I. J., \& Park, K. Y. (1989). Modeling of fluidized bed chlorination of rutile. Metallurgical Transactions B, 20(6), 959-966.

19- Jazini, M. H., Ghoreishi, S. M., \& Dadkhah, A. A. (2010). Modeling of Carbochlorination of Zircon in Fluidized Bed Reactor. Metallurgical and Materials Transactions B, 41(1), 248-254.

20- Horio, M., \& Nonaka, A. (1987). A generalized bubble diameter correlation for gas solid fluidized beds. AIChE journal, 33(11), 1865-1872.

21- Shiau, C. Y., \& Lin, C. J. (1991). Equation for the superficial bubble phase gas velocity in fluidized beds. AIChE journal, 37(6), 953-954.

22- Davidson, J. F., \& Harrison, D. (1963). Fluidized ParticlesCambridge Univ. Press, Cambridge.

23- Peters, M. H., Fan, L. S. and Sweeney, T. L., 1982, Reactant dynamics in catalytic fluidized bed reactors with flow reversal of gas in the emulsion phase. Chem. Eng. Sci. 37, $553-565$.

24- Spink, D. R., Cookston, J. W., \& Hanway Jr, J. E. (1968, January). FLUIDIZED-BED CHLORINATION OF ZIRCONIUM-BEARING MATERIALS. In Met. Soc. Conf., 34: Pt. 1, 375-84 (1968). Carborundum Metals Co., Akron, NY. 
Table1. Operating conditions of FBR in semi-batch mode

\begin{tabular}{|c|c|}
\hline Quantity & Value \\
\hline $\mathrm{Cl}_{2}$ flow rate & $2 \mathrm{~L} / \mathrm{min}$ \\
\hline Superficial velocity of $\mathrm{Cl}_{2}$ in the bed & $5 \mathrm{~cm} / \mathrm{s}$ \\
\hline Weight of $\mathrm{C} / \mathrm{ZnO}_{2}$ mixture & $2 \mathrm{Kg}$ \\
\hline Weigh percent of carbon in the mixture & $20 \%$ \\
\hline electric current & $200-250 \mathrm{~A}$ \\
\hline Voltage & $50-60 \mathrm{~V}$ \\
\hline
\end{tabular}

\section{$\underline{\text { Figure captions }}$}

Fig. 1: The SEM images of (a) carbon and (b) zirconia.

Fig. 2: The XRD analysis of (a) carbon and (b) zirconia.

Fig. 3: Schematic representation of the pilot-scale fluidized bed reactor (FBR) with its ancillary equipment.

Fig. 4: The flow sheet of the electro-thermal fluidized bed chlorination process.

Fig. 5: Schematic diagram of three-phase model.

Fig. 6: Simulation flow diagram of fluidized bed reactor.

Fig. 7: Output gas concentration versus time.

Fig. 8: zirconia conversion vs reaction time at different temperatures of 800, 1000 and 1200 ${ }^{\circ} \mathrm{C}$ and (A) mean particle size of $70 \mu \mathrm{m}$; (B) mean particle size (MPS) of $100 \mu \mathrm{m}$; (C) MPS of $130 \mu \mathrm{m}$.

Fig. 9: XRD of the produced $\mathrm{ZrCl}_{4}$ in the fluidized bed reactor. 

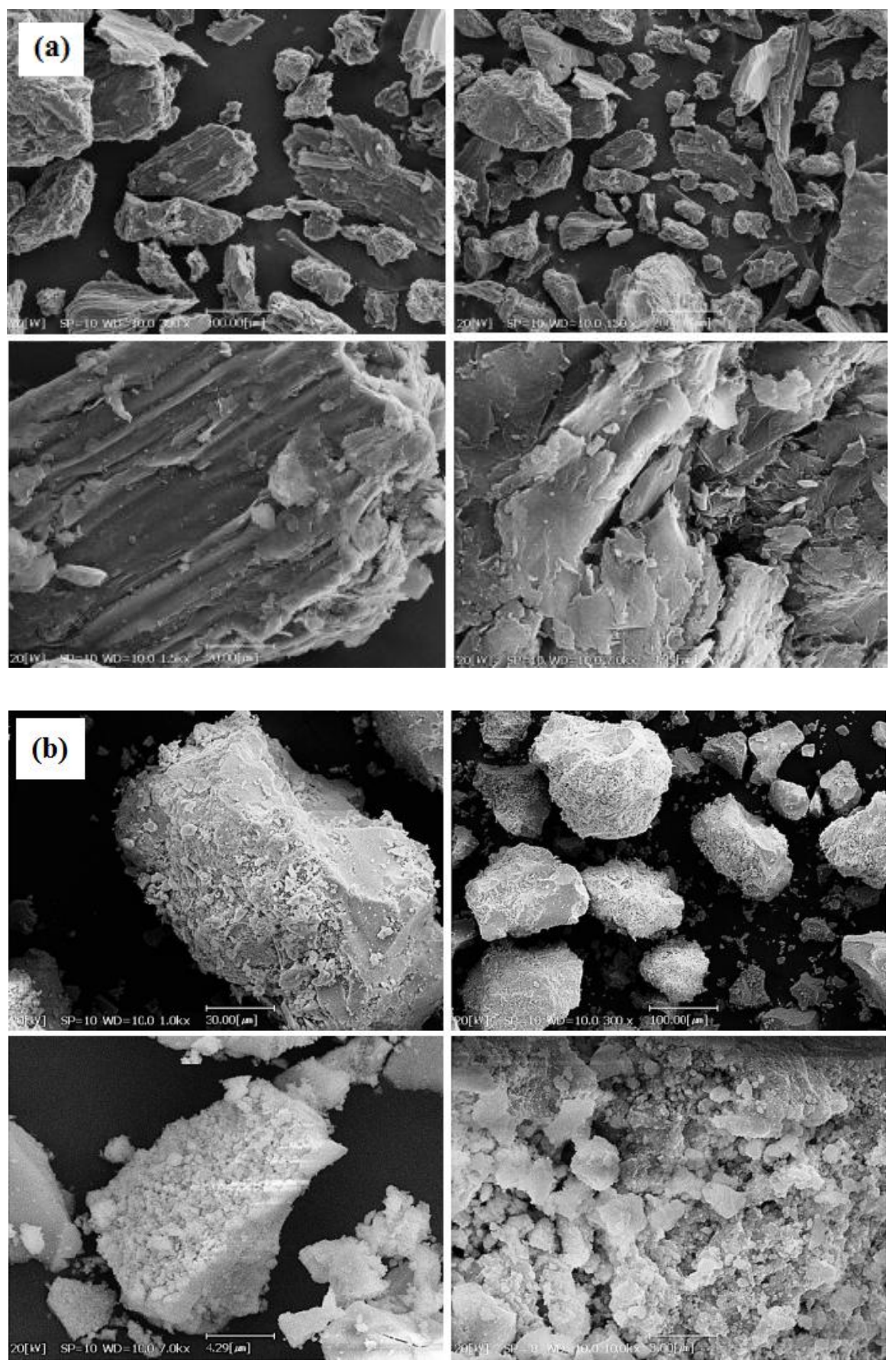

Fig. 1 
(a)

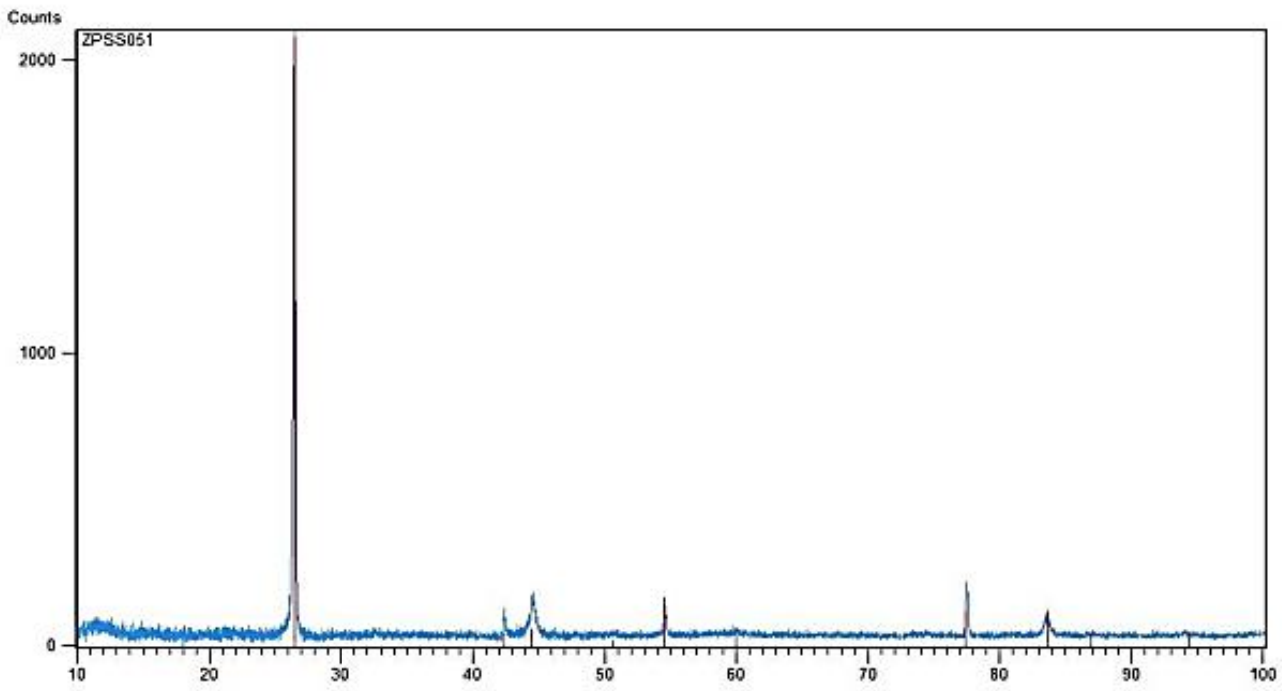

Sample Identification and Quantification

\begin{tabular}{|c|c|c|c|c|}
\hline Line color & Ref.Code & Compound Name & Formula & Crystal S. \\
\hline- & $00-012-0212$ & Graphite & C & Hexagonal \\
\hline
\end{tabular}

(b)

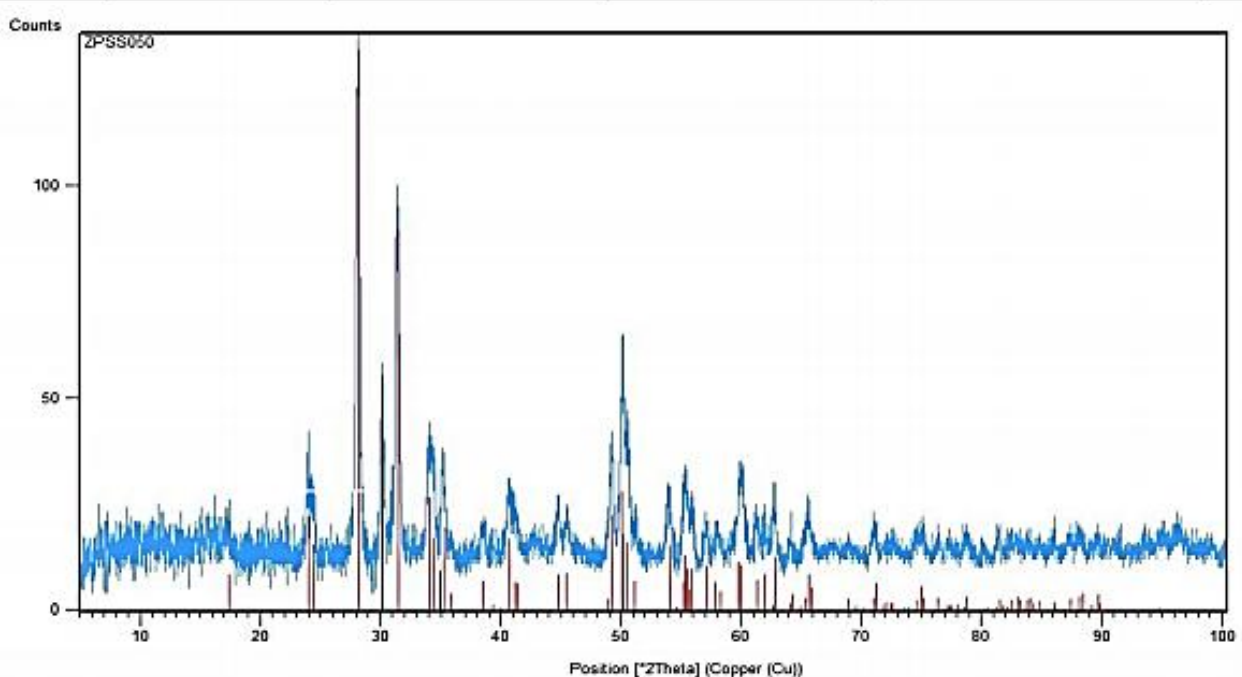

Sample Identification and Quantification

\begin{tabular}{|c|c|c|c|c|}
\hline Line color & Ref.Code & Compound Name & Formula & Crystal S. \\
\hline- & $01-078-1807$ & Zirconium Oxide & $\mathrm{ZrO}_{2}$ & Monoclinic \\
\hline- & $00-049-1642$ & Zirconium Oxide & $\mathrm{ZrO}_{2}$ & Cubic \\
\hline
\end{tabular}

Fig. 2 


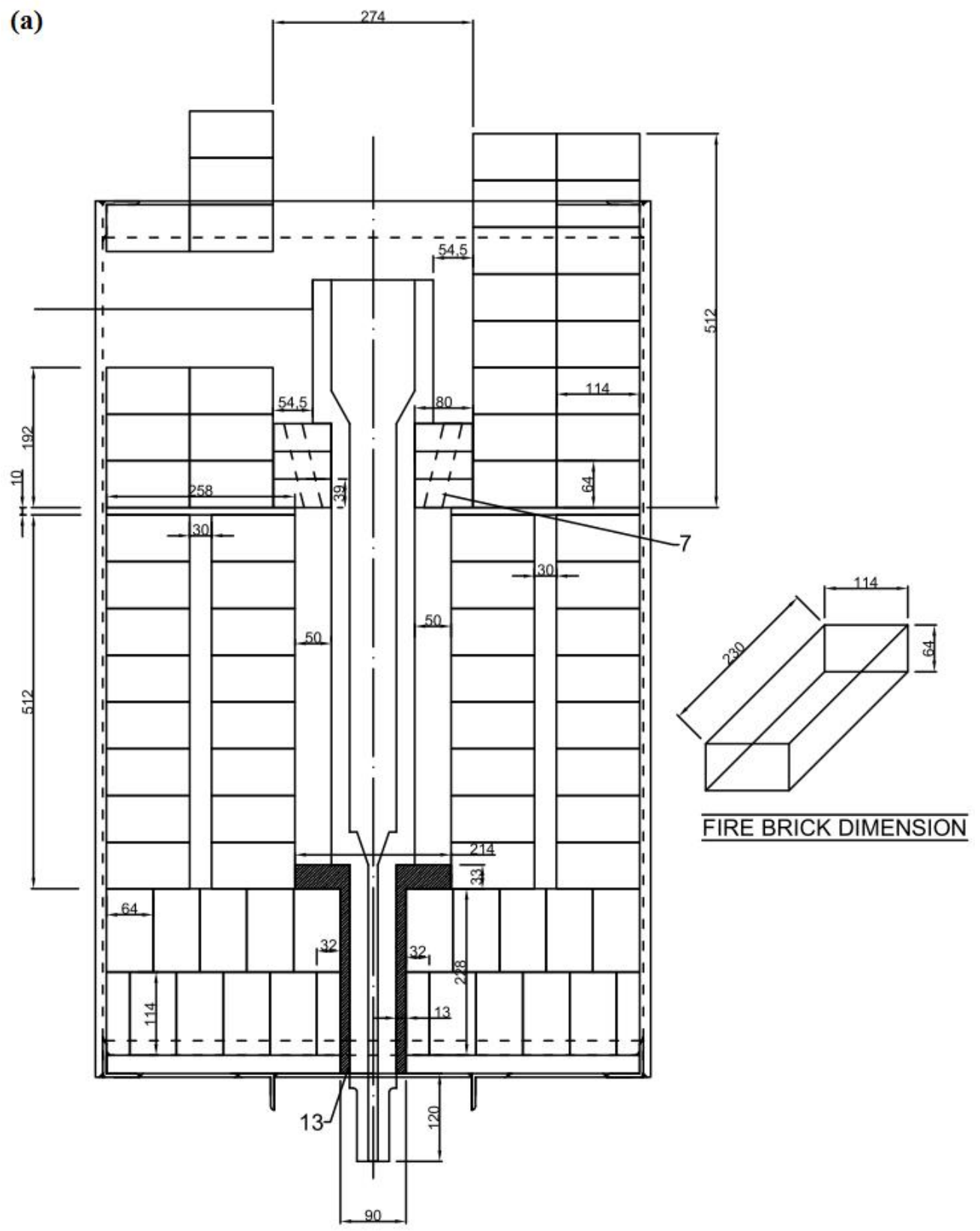

NOTE : ALL DIMENSIONS ARE IN MM 
(b)
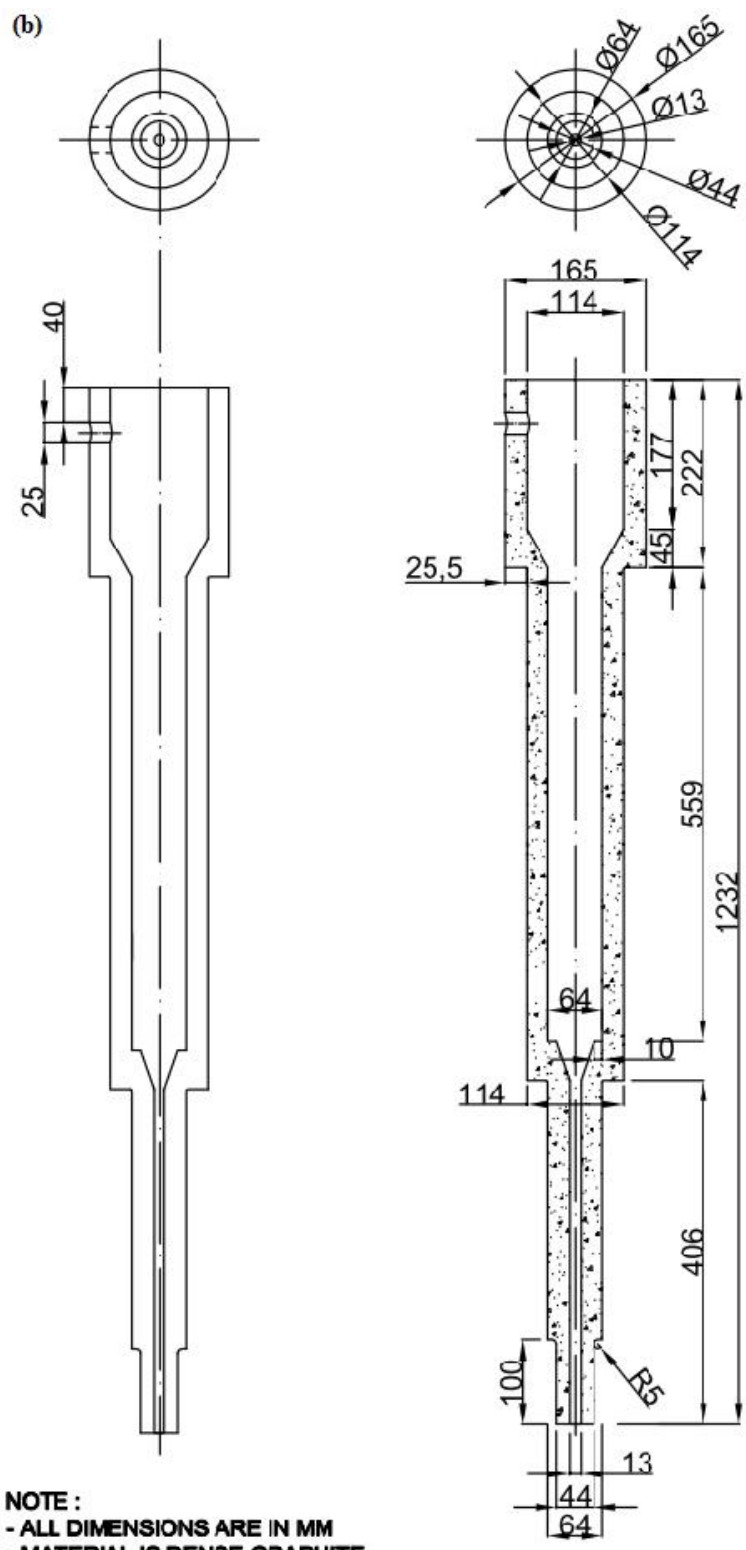

NOTE :

- ALI DIMENSIONS ARE IN MM

- MATERIAL IS DENSE GRAPHITE

Fig. 3 


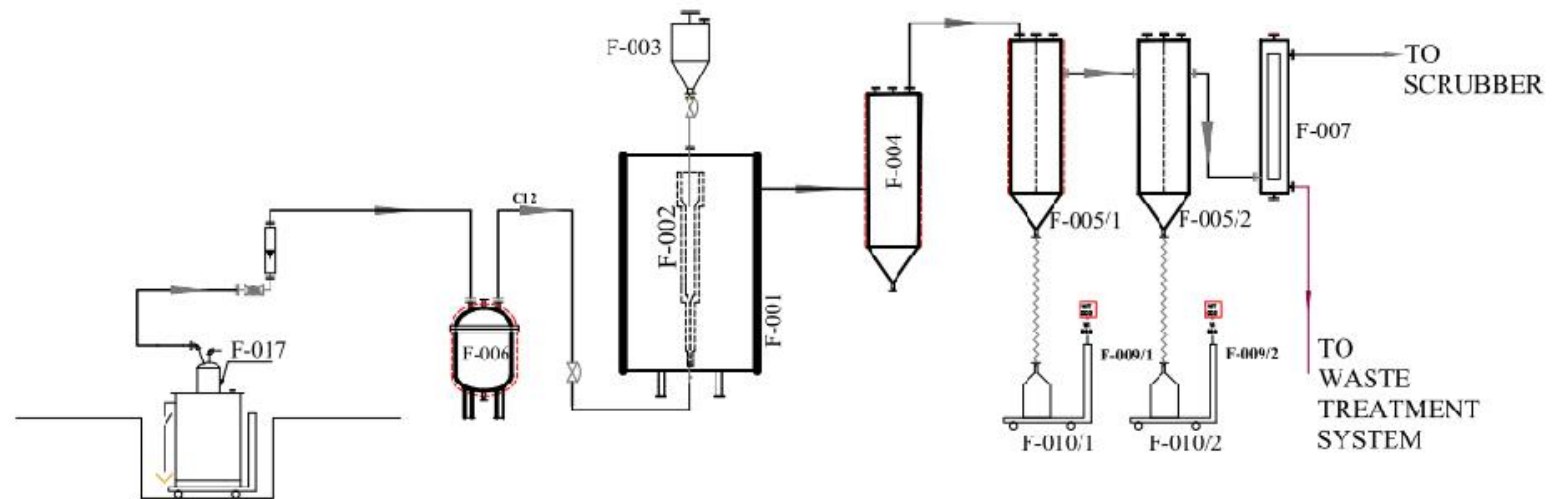

\begin{tabular}{|c|c|c|c|c|c|c|c|c|c|c|}
\hline EOUIPMENT NUMBER & $F-001$ & $\mathrm{~F}-002$ & $F-003$ & $F-004$ & $F-005 / 1,2$ & $F-006$ & $\mathrm{~F}-007$ & $\mathrm{~F}-009 / 1,2$ & $F-010 / 1.2$ & $F-017$ \\
\hline EQUIPMENT NAME & FURNACE & \begin{tabular}{|c|} 
ELECTRO \\
THERMAL \\
FUIDIZEBED
\end{tabular} & HOPPER & CYCLONE & CONDENSER & BUFFER & SCRU3BER & SCALE & SLAG TANK & Q2 CTLNDER \\
\hline OP'ERAIING IEMP,(“C) & $500 \sim 1200$ & $500 \sim 1200$ & AMB & 500 & 250 & 100 & AMB & AMB & 50 & 38 \\
\hline OPERATING PRES.(barg) & ATM & АTM & ATM & 0.83 & 0.83 & 1 & 1 & ---- & 0.83 & 50 \\
\hline $\begin{array}{l}\text { MATERIAL OF } \\
\text { CONSTRUCTION }\end{array}$ & $\begin{array}{c}\text { ASTM } \\
\text { A2B3OR.C }\end{array}$ & GRAPHITE & $\begin{array}{l}\text { ASTM } \\
\text { A2B30R.C }\end{array}$ & SS 321 & SS 321 & 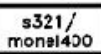 & PVC & ST37/321 & SS 321 & ST37 \\
\hline
\end{tabular}

Fig. 4 


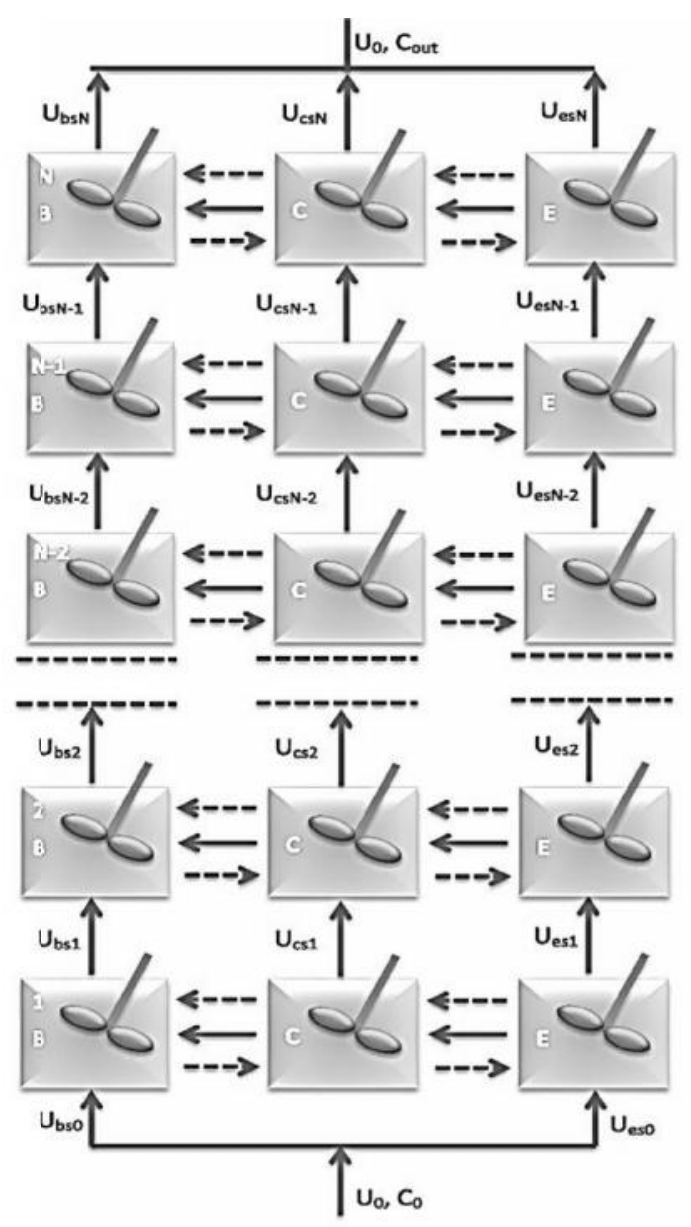

Fig.5 


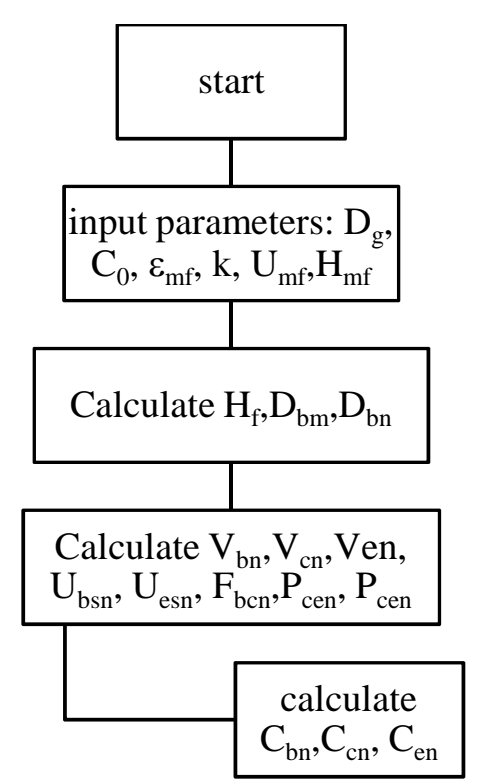

Fig. 6 


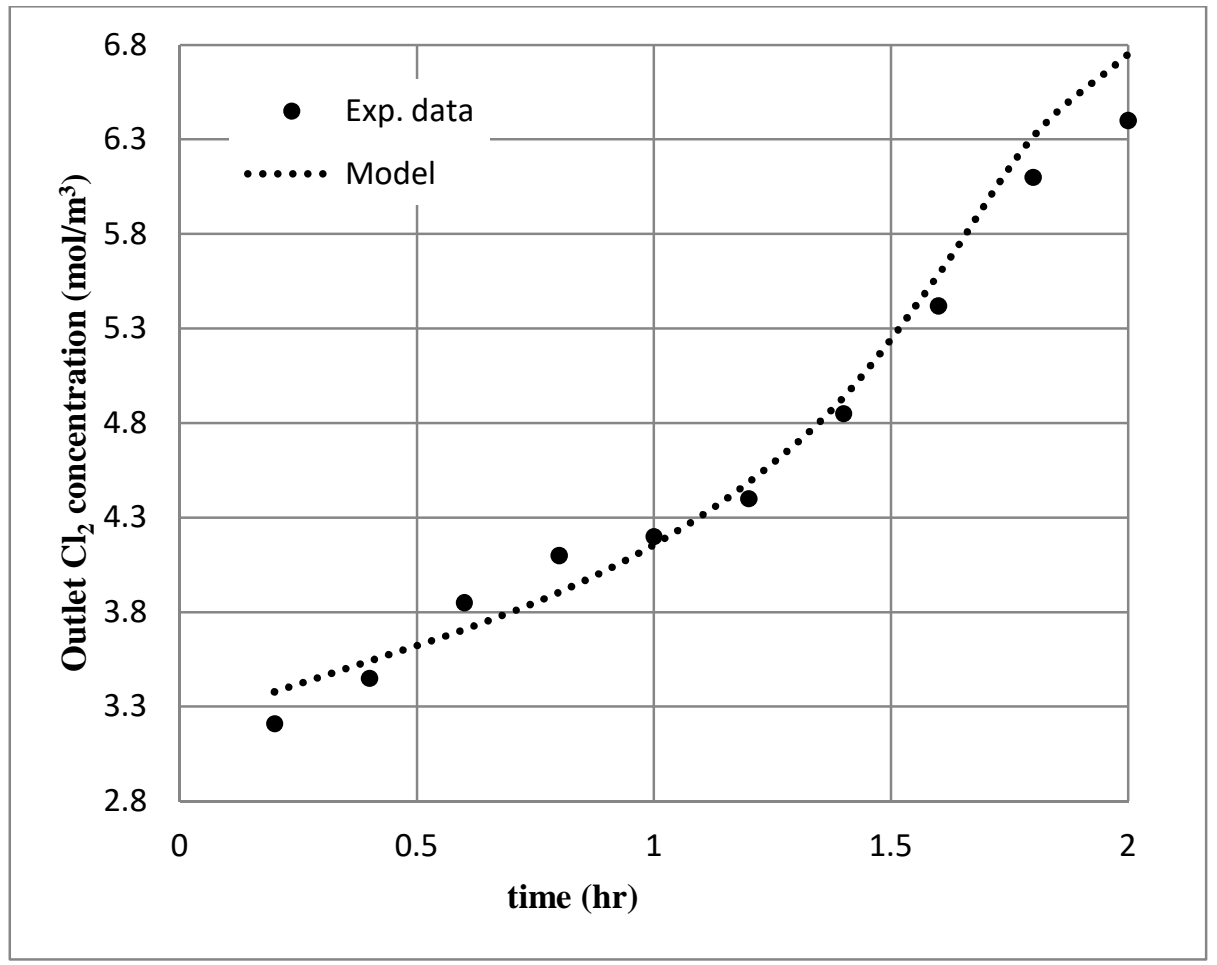

Fig. 7 
(A)

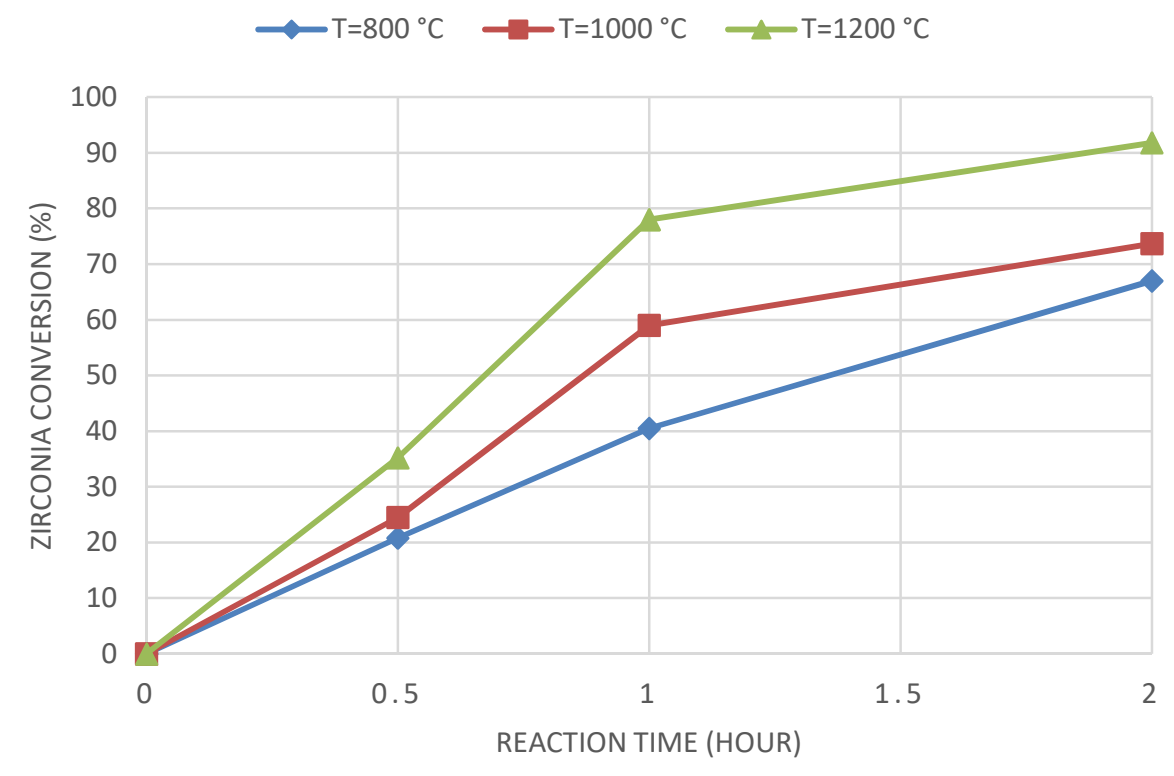

(B)

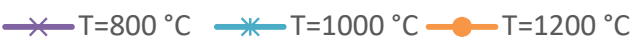

$\diamond \mathrm{T}=800^{\circ} \mathrm{C} \quad \square \quad \mathrm{T}=1000^{\circ} \mathrm{C} \quad \Delta \quad \mathrm{T}=1200^{\circ} \mathrm{C}$

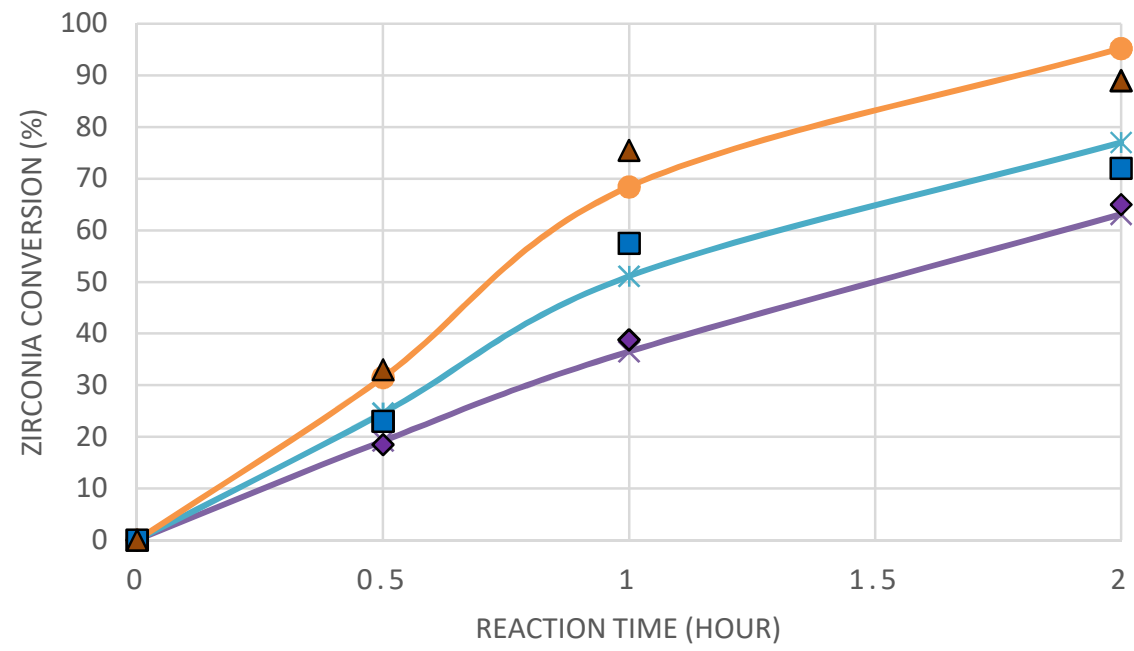


(C)

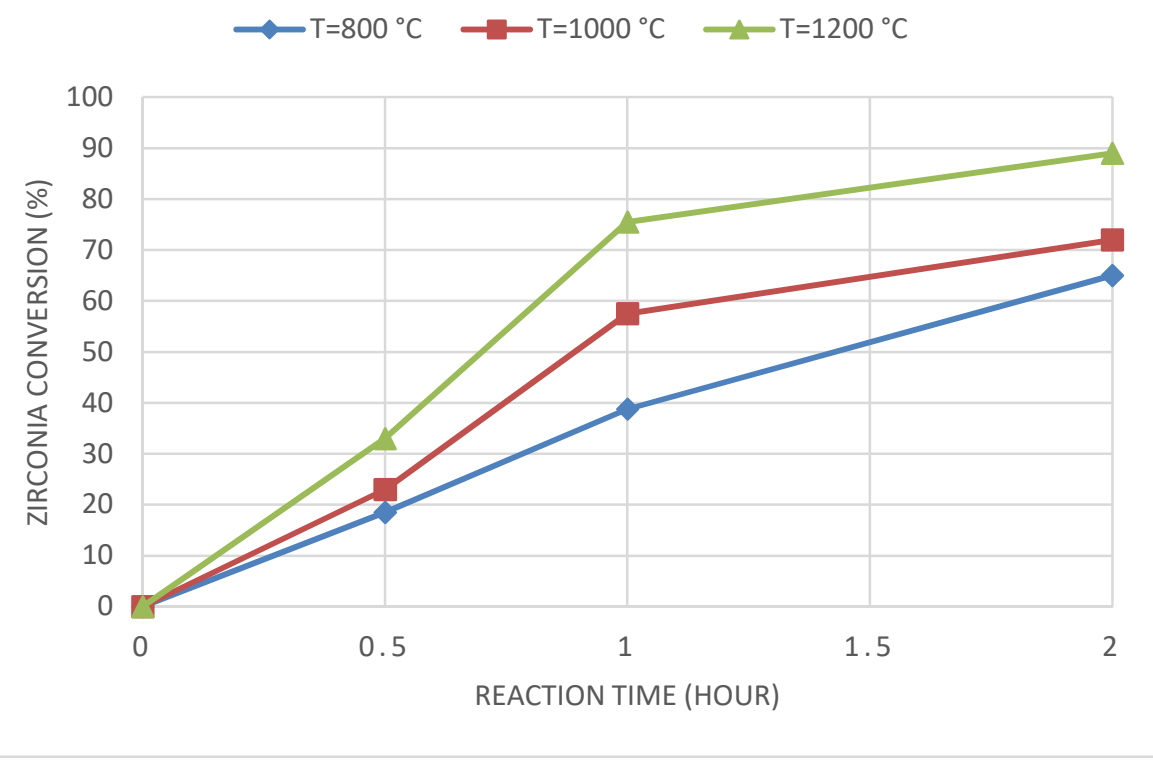

Fig. 8 


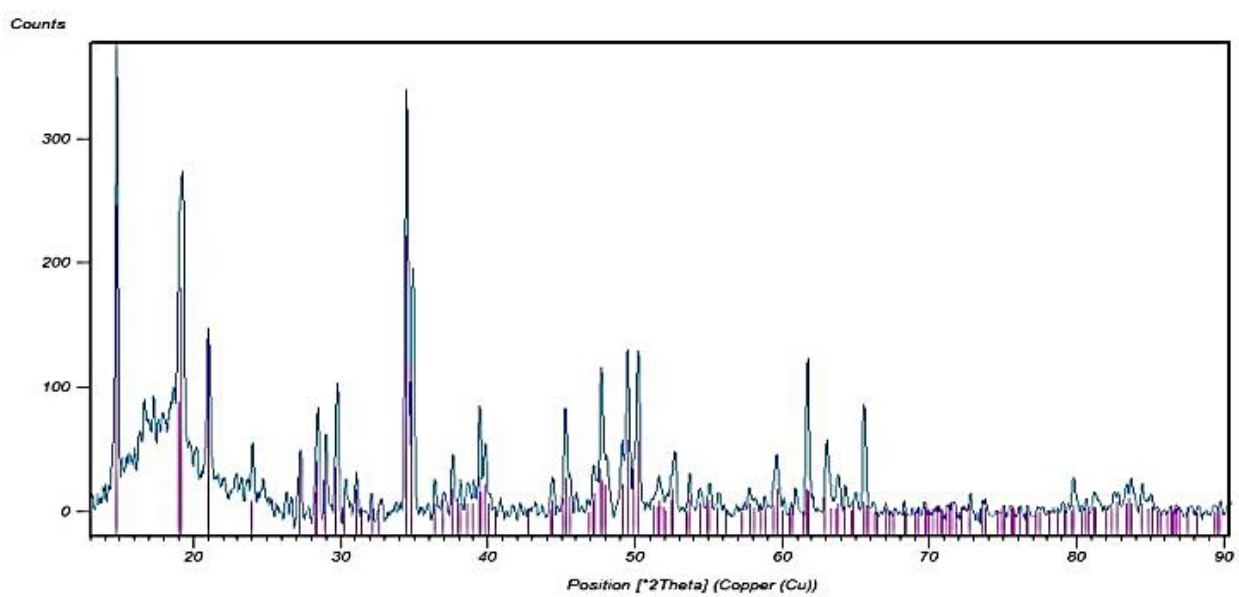

Sample Identification and Quantification

\begin{tabular}{|c|c|c|c|c|}
\hline Line color & Ref. Code & Compound Name & Formula & Crystal S. \\
\hline & $01-072-1054$ & Zirconium Chloride & $\mathrm{ZrCl}_{4}$ & Monoclinic \\
\hline
\end{tabular}

Fig. 9

How to cite this article:

Ghasemi M R, Ghoreishi S M. Dynamic simulation of carbochlorination of zirconia in a pilot plant fluidized-bed reactor. J. Fundam. Appl. Sci., 2017, 9(1S), 623-646. 